\title{
Healthcare providers and Caregivers' perspectives on factors underlying the persistent malnutrition of Children aged 0-59 months in Buhweju district, southwestern Uganda
}

Abaasa N Catherine ( $\nabla$ acatherine@must.ac.ug )

Mbarara University of Science and Technology(MUST) https://orcid.org/0000-0001-6882-1831

Godfrey Zari Rukundo

Mbarara University of Science and Technology(MUST)

Savino Ayesiga

Mbarara University of Science and Technology(MUST)

Susan Pearl Atukunda

Uganda Industrial Research Institute

Susan Campisi

Great Ormond Street Hospital For Children NHS Foundation Trust

Shawna O'Hearn

Global Health, Faculty of Medicine, Dalhousie University

Noni MacDonald

Global Health, Faculty of Medicine, Dalhousie Univesrity

Research article

Keywords: Stunting, wasting, Malnutrition

Posted Date: October 14th, 2020

DOI: https://doi.org/10.21203/rs.3.rs-48098/v2

License: (9) (i) This work is licensed under a Creative Commons Attribution 4.0 International License.

Read Full License

Version of Record: A version of this preprint was published at BMC Public Health on August 3rd, 2021.

See the published version at https://doi.org/10.1186/s12889-021-11432-1. 


\section{Abstract}

Background The nutritional well-being of infants and young children is influenced by economic, environmental and maternal factors that range from food intake, health, sanitation and care. All regions of Uganda have registered unacceptably high levels of childhood malnutrition over the years, although with an uneven distribution across regions. This study assessed health provider and caregiver perspectives on factors responsible for persistent malnutrition among children aged 0-59 months in Engaju and Nyakishana sub counties in Buhweju district.

Methods In this phenomenological qualitative study, we conducted six Focus group discussions with Village Health Team members and care takers of children aged 0-59 months in Engaju and Nyakishana sub-counties and two key informant interviews with two members of the district health team to explore their perceptives on the factors responsible for persistent malnutrition in Buhweju District in May 2018. Data were thematically analyzed manually and using Atals $\mathrm{Ti} 7.5$

Results Historical and geographical challenges, poverty and economic occupation, parental alcoholism and domestic violence as well as inadequate childcare services were identified as factors responsible for persistent malnutrition among children aged 0-59 months in Engaju and Nyakishana sub counties in Buhweju district

Conclusion Persistent malnutrition in children aged 0-59 months in Buhweju district is mainly due to historical and geographical challenges and its associated factors that include poverty and economic occupation, parental alcoholism and domestic violence and inadequate childcare services. Addressing these factors from the grassroots up through, multisectoral collaboration between infrastructure, Agriculture, Education and health, engaging communities and effective policy changes and implementation has the potential to improve the nutrition status of children in Buhweju district

\section{Background}

Nutritional wellbeing is fundamental to the attainment of the full social, economic, mental and physical potential of individuals, communities and populations (1-3). Factors associated with malnutrition happen at local, regional, national and international levels. They range from environmental, social, economic, socio-demographic and political causes that are deeply interrelated, and mutually affect each other (4). In Uganda, malnutrition has been associated with immediate, basic and underlying factors as well as food prices, poverty and unemployment (5). Children whose parents engage in agriculture and manual work, peasant farmers or employed by non-family members, as well as age of the mother, and age and sex of the child are at higher risk of stunting and underweight compared to the children from pastoralists' families $(6,7)$.

Although all regions of Uganda have registered unacceptably high levels of childhood malnutrition over the years, the distribution has not been even (8). A 2017 report noted that approximately, 11 percent of all children were underweight and 2 percent severely underweight with children in rural areas slightly more 
likely than those in urban areas to be underweight (11 percent and 8 percent, respectively)(9). The western region of Uganda has persistently registered the highest levels of childhood malnutrition especially stunting, yet, this is the region with plentiful food production and is sometimes referred to as "the food basket" of the country $(10,11)$. In the Ankole region of southwest Uganda, children under 5 years $29.3 \%$ were stunted, similar to a national average of $29.0 \%$ but Buhweju district had stunting levels of $51 \%-55.6 \%(9,12)$. Anecdotal data from Buhweju District and from partners indicated the highest prevalence of malnutrition with young children was in sub-counties of Engaju and Nyakishana.

Therefore, this study assessed health provider and caregiver perspectives on factors responsible for malnutrition among children aged 0-59 months in two Buhweju district sub counties of Engaju and Nyakishana in South West Uganda in May 2018.

\section{Methods}

\section{Study setting}

Buhweju is a rural District in Southwestern Uganda with a population of 124,044 , with hilly geographic terrain and hence poor infrastructure including road network (9). The population is mainly employed in agriculture practicing subsistence farming and/or working on tea and coffee plantations. Some male members of the community work in the gold mines.

\section{Recruitment and eligibility of the study participants}

This was a phenomenological qualitative study. Caretakers of children aged between 0 to 59 months, as well as the District Health Officer, nutrition focal person (a nurse with nutrition training) and community health workers known as Village Health Team (VHT) members were purposively sampled from communities in Engaju and Nyakishana sub-counties and at the district. The VHT coordinators in these communities assisted in recruitment by identifying caretakers and VHT leaders as they are health gatekeepers to these communities. The identified participants were approached by the study team who introduced the study to the participants by explaining the study purpose and objectives. Participants were eligible if they were above 18 years of age; and were 1) only one caretaker selected per family of observed malnourished children aged between 0 to 59 months and resided in Engaju and Nyakishana sub counties; 2) VHT members in Buhweju district, 3) Nutrition focal person and District Health Officer of Buhweju district. Participants who did not meet this criterion were excluded from the study. All those approached met the inclusion criteria and agreed to participate. Two focus group discussions with VHT members, two focus group discussions with caregivers were carried out in each of the two sub-counties of Engaju and Nyakishana in Buhweju district and two Key informant interviews were conducted.

\section{Interview and Focus group discussion Procedures}

Interview guides for the key informant and focus group discussions were developed to explore healthcare providers and caregivers' perspectives on factors underlying the persistent malnutrition of children aged 
0-59 months in Buhweju district, southwestern Uganda. The probe interview guide questions included a) What are the factors responsible for malnutrition of under five in Engaju and Nyakishana sub-counties of Buhweju district? (family, community, health care, economic, cultural and political) b) What have people done at the family level to improve child nutrition in Engaju and Nyakishana sub-counties of Buhweju district? (Primary, Secondary, Tertiary factors). These questions were derived specifically from the study objectives. The interviews and focus group discussions were conducted in Runyankore-Rukiiga, the local language, by the study team using interview guides translated into Runyankore-Rukiiga, and back translated into English to ensure that the message was correctly translated. The study tools were first piloted with a nutrition focal person at Mbarara Regional Referral Hospital and caretakers of children 0-59 months of age in Nyamitanga division, Mbarara Municipality, Mbarara district for Key informant interviews and Focus group discussions respectively. Necessary changes were implemented. The interviews and focus group discussions with the participants were conducted at a private location at the convenience of the different participants at the time agreed upon with the study team. They were not paid for participating in the study but their transport costs were covered. The interviews were conducted by the study team and a trained Research Assistant between May and June 2018. The interviews lasted between 60 and 90 minutes, were audio recorded and field notes taken. Interviews and discussions were conducted until indicative thematic saturation was achieved. Each audio recorded focus group was comprised of 8-12 male and female participants. Study staff also recorded observations through notes during the focus group discussions.CA did the moderating; SA took notes while NP did the recording of the interviews and discussions.

\section{Data Management and analysis}

Audio recordings were listened to by CA, SA and NP every after the day's work. They were transcribed sequentially on the daily basis by CA, SA and NP which helped in giving a deeper insight into the inquiry during the data collection process inline with the study objectives. The data was translated by Research Assistant(NP) and checked by CA and SA. Data analysis was done through different stages of familiarization with data, dual coding was employed. Two members of the research team (GZR and SA) independently read through the transcripts and identified emerging themes and manually identifying corresponding quotes by highlighting them with different colors per theme. Data management from interviews and Focus group discussions were analyzed differently and merged later incorporating data from audio recordings, verbatim notes and nonverbal observations during the interview and discussion processes. A codebook with sections for parent themes, sub themes, description and illustrative quotes was developed. Twelve emerging themes were identified. The identified themes were compressed into four grouped themes. Indicative thematic analysis was done by analyzing statements from participants, identifying commonalities, developing themes and sub themes. The same data was entered into Atlas $\mathrm{Ti}$ 7.5. Using the identified themes, each transcript was re-analyzed to reveal the best corresponding quotes. The same process was done for key informant interviews and Focus group discussions data.

\section{Results}


A total of 24 males and 49 females composed the different focus group discussions in the two subcounties (See table 1). All participants, both male and female were subsistence farmers though some males and females worked on the tea and coffee plantations and local gold mines. The two (2) key informants were a male district health officer and a female district nutrition focal person. They were all employed by Buhweju district local government and each had worked for the district for more than a year at the time of the study.

Table 1. Study participants

\begin{tabular}{|l|l|}
\hline & Frequency \\
\hline Focus Group Discussions & 6 \\
\hline Key Informant Interviews & 2 \\
\hline Sub counties & 2 \\
\hline Males & 24 \\
\hline Females & 49 \\
\hline
\end{tabular}

Four broad themes (See table 2) were generated (a) historical and geographical challenges (b) poverty and economic occupation (c) alcoholism and domestic violence (d) inadequate child care services.

Table 2: Codes, themes and subthemes

\begin{tabular}{|c|c|c|}
\hline Codes & Themes & Sub themes \\
\hline Lack of nutrition services & \multirow{3}{*}{$\begin{array}{l}\text { Inadequate child } \\
\text { care services }\end{array}$} & Breast feeding practices \\
\hline $\begin{array}{l}\text { Nutrition issues are not given priority } \\
\text { they deserve }\end{array}$ & & Barriers to immunization \\
\hline Poverty & & Family planning \\
\hline $\begin{array}{l}\text { Food production and care for children } \\
\text { is considered a role for women }\end{array}$ & \multirow[t]{3}{*}{$\begin{array}{l}\text { Poverty and } \\
\text { economic occupation }\end{array}$} & \\
\hline Alcoholism & & \\
\hline Domestic violence & & \\
\hline Low level of education & \multirow{3}{*}{$\begin{array}{l}\text { Alcoholism and } \\
\text { domestic violence }\end{array}$} & \\
\hline $\begin{array}{l}\begin{array}{l}\text { Location, terrain and access of } \\
\text { Buhweju }\end{array} \\
\end{array}$ & & \\
\hline Water and sanitation & & \\
\hline Economic Occupation & \multirow{2}{*}{$\begin{array}{l}\text { Geographical and } \\
\text { historical challenges }\end{array}$} & \multirow{2}{*}{$\begin{array}{l}\text { Communities use local } \\
\text { herbs/ traditional medicines }\end{array}$} \\
\hline $\begin{array}{l}\text { Health services availability and } \\
\text { Utilization }\end{array}$ & & \\
\hline
\end{tabular}


Buhweju was an underserved county in greater Bushenyi district. The district lacks enough public services such as road network and has few health facilities to serve a population of 124,044 people (UBOS, 2014). The majority of the people are not educated with generally low educational achievements.

"There is a problem of education whereby youths don't want to go to school all they do is waking up very early and go to play pool and whatever you cooked for your children, they will come at night and they eat and sometimes you find that you have your crops in the store. The youths and men steal them so as to get money to play the pool and buy alcohol" FGD -VHT.

There is poor road network hence transport is poor. There were underserved areas, some without health centers and even when accessed the centres lacked medicines. There was a lack of health facilities, only one Health Centre for the whole sub-county. There was only one Medical Officer in the entire district despite the fact that according to Uganda Health Policy there should be health services provision starting at local council/village level. There was limited interaction between the health workers and community members. There were a limited number of health workers all of whom felt overworked and overwhelmed leading to no time to spend on educating the community.

"We do what is within our level and healthy facility, we do a lot of referrals since health centres are inadequate to serve and cover the demands of the population and we have realized that nutrition which can be handled at different levels of the facilities can only be handled at Health Centre 111, Health Centre $1 \mathrm{~V}$ while the lower facilities which are very few only do assessments" Healthcare provider-KII.

"If I compare those sub-counties that consistently remain in red in acute malnutrition they are underserved areas and there are some without healthy centers and access to them is not easy like if you went to Engaju the furthest are you would have appreciated they need to travel more than about $10 \mathrm{kms}$ to access a health center even if the whole staff that are there, they are overwhelmed they don't have time to interact with those individuals and educate them" Healthcare provider-KII.

"........ in Buhweju we have a thing of witchcraft(mahembe) so you realize that the community is in that tradition and it's blindfolding for them instead of fighting against malnutrition, they are looking for who to help them in witchcraft and by the time they go to the facility and tell them it's malnutrition FGD-VHTs.

I realized that there is a knowledge gap within the community because we expect the community to take some of these things but they seem not to because they think that this issue doesn't need to get to the health facility. I am worried in the community there are very many children we are losing since the entire community including leaders don't have enough knowledge about nutrition" Healthcare provider KII.

Due to the poor terrain of Buhweju, constructing of latrines was hard. The sanitation was poor with sanitation in Engaju sub-county at $43 \%$. The lack of latrines increased the risk of dysentery as did the lack of water for handwashing with the few available latrine structures. 
"There are no systems within the sub-counties to make sure the issue of nutrition and hygiene are followed and the issue of waste management. The health assistant within a sub-county usually visits these communities to make sure these activities are done and does healthy education but we realised that all these systems are not there" Healthcare provider -KII.

There was a lack of political will at low-level councils to advocate for change.

"In Buhweju we need political will which isn't there at all levels, there are gaps that's why we came up with multi-sectoral approach and we brought in political leaders and we try to train them and engage them into nutrition and HIV to get to know the situation and they try to push and see some of the issues and gaps that need to be covered but not leaving it to DHOs" Healthcare provider-KII..

Political leaders were money minded. This led to selective donations from the government based on political orientations for example provision of seeds. Social services from the government did not reach the communities as that money was taken by local leaders

"Sometimes we hear that the government has sent certain support but we don't see such support but we think others get or sometimes they bring like beans and they give like 3 people who supported them and they leave others behind" FGD-Caregivers

\section{Poverty and economic occupation}

Healthcare providers reported limited government funding for nutritional programs (food support, nutrition assessment and deworming programs) in Buhweju district compared to other districts. The communities practice subsistence farming but because of poverty, they often end up selling all the produce leaving families with little to eat. In household food theft by men also occurred with the men stealing even the little that was available from their wives and using their money earned on tea plantation or in the gold mines to buy alcohol.

The women were left to care for their families with money using the women earned for selling produce and working on tea and coffee plantations. The communities lived in poor housing structures and the sanitation was also very poor. There was a high incidence of diseases ranging from diarrhea, malaria and HIV/Aids that also affected the nutritional status of the vulnerable children. Because of the gold mining in the area, children dropped out of school to work in the mines, where they were underpaid/ exploited by middlemen and the little they were paid was used for themselves to buy alcohol, gamble or to play pool. Gold mining also led to high school dropouts (child labor).

"In Buhweju, ideally they are cultivators but with this development that has come in with these murram roads that have been extended all food is sold off even today as I was coming I met a full lorry carrying matooke (bananas) to Bwizibwera trading centre because they need money and don't spare anything for themselves "Healthcare provider-KII. 
"our men in Buhweju don't want to support us, their role is going to the bar to drink and stealing our crops after harvesting and you find that you have no lunch and supper for our children and that leads to malnutrition "FGD-Caregivers

......"Buhweju, there are few people working for the government so when we fix our eyes on men our children will die of malnutrition because men don't care" FGD-VHTs.

Having to focus mainly on cash crops, not food crops, takes so much of their time there is little time left to prepare food for their families

"We have seasonal income because for us we depend on tea and coffee and after harvesting like 3bags of coffee and given like 700000 UGX shillings, you don't know how the man spent it he can come home with like 200000 shillings and he tells you to put it back in coffee and he tells you that that's the only money he got and you find that you need school fees and find that you have no balance for feeding the children so they fail to plan for the children because that money is not enough" FGD-Caregivers.

Subsistence farming was not always successful due to poor yields, available land not being very fertile, lack of enough land for cultivation, and limited crops chosen to cultivate so no greens to feed on and no chicken for eggs.

"Lack of farming space, because when one has enough land, he /she can rear chicken, cows as well as plant some greens and grow enough food for home consumption and sell for school fees but when one doesn't have land, our children end up being malnourished" FGD-Caregivers.

\section{Alcoholism and domestic violence}

Men were not seen as supportive with most caregivers and VHTs reporting of alcohol abuse and high rates of registered domestic violence. Women lived in constant fear leading to limited food production and psychological distress impacting their ability to care and feed for their children. When men returned home drunk, a usual condition, they ate the food the mother had prepared for the children. These children were left hungry and malnourished. What they earned from commercial agriculture (tea plantations) was not allocated to buying food but was used by men to buy alcohol while the women often bought dresses. Men also spent money on playing pool and gambling.

"If I had money, I would prefer having local food available because if you have money and you prefer going to alcohol and expensive new dresses it's not good because I interacted with mothers and they were like we can't buy food when I dig from morning to evening when the man and takes everything like if he gives me 100k I would also go and buy a new dress I can't buy food so the challenge is how to use it" Healthcare provider-KII.

"Domestic violence! Whereby the man beats the wife and she runs to sleep in the bush and men don't have time for children because for them in the morning they must go to the bar and no one to cook for them so the child will eat whatever he /she finds because you find that a woman sleeps only for two days 
in the house and 5 days sleeps outside and even when she is at home, she has to hurry before the husband comes and pours away the food even they fight at night the man goes to the bar with the remaining beans to exchange them for a drink and he leaves the wife and children with nothing to eat so this causes hunger hence leading to malnutrition among children because the food they eat is not good for them" FGD-VHTs

\section{Inadequate child care services}

Malnutrition in Buhweju was associated with a number of factors that were reflective of inadequate health care services including inadequate nutritional services, low levels of immunization, lack of adequate family planning, lack of childcare knowledge and inadequate treatment modalities available.

There was a lack of adequate implementation of general nutrition services in Buhweju as shown by the low availability of health workers and few health centers and consequently mothers required to travel long distances (mostly on foot), to seek assessment and treatment of nutritional related conditions. Due to the limited capacity of the Health Centers, only nutritional assessment and counseling were offered, and cases of severe acute malnutrition (SAM) were referred to hospitals several miles away without additional support to ensure that the child reached there and received the necessary care. The VHTs lacked sustainable funding to help them complement the inadequate health care human resource. In addition, local leaders were not cooperative in assisting with implementation of known community based nutrition programs and this further impeded the VHTs potential to complement the implementation capacity of nutrition program.

"We do referral and counselling... it's the only thing we offer so we counsel the mother on what the child needs to eat and if the child doesn't need referral they get back to the community. For those who need to be referred, we do." Health care provider-KII

Our leaders don't cooperate with us but their role is to approve referral by putting a stamp on documents, but sometimes they refuse to approve referral and even when you call them for certain health talks, they refuse and yet people would listen to them than us FGD-VHTs.

Caregivers in Nyakishana and Engaju reported feeding their children on only a few foods; mainly matooke (type of bananas) and a few times with dodo (greens). This food was limited in access, quality and quantity since most of what is cultivated was sold to raise money to meet other family responsibilities. In addition, the banana plantations were destroyed by banana wilt disease. On other occasions, some care takers did buy posho (Maize meal), sweet potatoes and cassava which their children fed on without sauce.

Poor feeding e.g. like feeding on a single type of food and eating each and every food is not good for babies' for example matooke (Bananas) without beans but salt and dodo (greens) (FGD-Caregivers).

There was limited supply of protein rich foods like milk and eggs since very few families owned cows or chicken. A few households fed their children on silver fish and soybean but this was seasonal, expensive 
and could often only be purchased at markets several kilometers by foot away from their homes.

....."in all of Buhweju apart from our demonstration gardens which we are trying to develop, you rarely find a vegetable garden at home, they don't rear animals, you find a goat in a few homes, there are no farms in Buhweju where you will get milk because I have never seen a farm in Buhweju yet these children need milk because they need all these things that will help them get better nutrition" Healthcare provider, KII.

Caregivers reported to be working for long hours in their gardens and tea farms that were very far from their homes. They leave early and return late when they are tired leading to a lack of time and willingness to prepare meals. Consequently, they prepare meals in large quantities with the intention that the food is to be consumed the following day.

......"Limited time for the children whereby you have to wake up very early in the morning going to the garden and you find that you have no time to prepare breakfast for children and even sometimes they have nothing at home to prepare for lunch so they just depend on left over" (FGD-Caregivers)

Village Health Teams and Caregivers reported poor breastfeeding practices. Mothers lacked knowledge of proper breastfeeding techniques. Mothers worked on family gardens far from home for long hours and returned home late leaving no time to breastfeed their children. The children are weaned early due to lack of time for breastfeeding, fluctuations in breast milk due to poorly fed mothers.

"......... You find a mother of a six months child breastfeeding the baby right from the garden with unwashed hands while doing other chores and the baby is feeding like a cow "FGD-VHTs.

"...........Sometimes we have no time for our children because we were advised to breast them at least 8 times a day but when you're busy digging on a family garden, you can't get time to breastfeed for all that period so by the time you go back home like at $2 \mathrm{pm}$, the child is already hungry and this leads to malnutrition" FGD-Caregivers.

Village Health Teams reported that caregivers donot know the purpose of immunization, so they end up forgetting the immunization days. Deworming medication is given at immunizations. Sometimes when they go, the vaccines and deworming medications were not enough to cover all the children. The caregivers claimed that with poor feeding, the vaccines were not important for their children. Due to so many demands on mothers, like digging from distant gardens, cooking and taking care of other family members, immunization and deworming were often not prioritized. Community leaders like pastors also preached against immunization hence making their followers shun immunization and hence did not receive deworming.

Sometimes we are not informed about immunization days so we end up missing immunization and deworming of our children but there is a VHT who normally moves around giving medicine to our children but if we did not have him our children wouldn't get immunized. 
Even some religions don't support polio immunization like one pastor said I can't immunize my child against polio and said he never treated any of his children but they are all fine. (FGD VHTs)

Caregivers reported a lack of access and knowledge on the available family planning services. Caregivers reported not using family planning due to many misconceptions. They believed that family planning affects their health hence negatively by impacting on the mothers' ability to do their routine work like digging and household chores. Since most women were the primary source of income for their families, they forewent family planning. On the contrary, mothers who were willing to use family planning were unable to get the s rvices from their nearby health units because of shortages and limited supplies.

Production of many children. like having 6 children in a compound of almost of the same age bracket due to fear of family planning because they say when you're on family planning, you're not supposed to overwork and yet when you're the one taking care of the entire family, you decide to leave it so as to be able to continue working hence leading to many children and that leads to malnutrition due to lack of enough food they can even be 20 children (that's how we think) FGD-Caregivers.

\section{Discussion}

We aimed at exploring perspectives of healthcare providers' and caregivers' on the factors associated with malnutrition of children aged 0-59 months in Buhweju district, rural south western Uganda. We found out that historical and geographical challenges, poverty and economic occupation, alcoholism, domestic violence and inadequate childcare services were the major factors that contributed to persistent malnutrition.

Buhweju district, formerly a county of Bushenyi district was an underserved county, due to a hilly geographical terrain, and poor road network hence poor social services. In our study, geographical terrain was found to be the major historical and geographical challenge leading to poor road network hence poor access to social services needed to meet community requirements. As noted by Dielemann and colleagues, to achieve food related sustainable development goals(SDGs) in Uganda; there is need to invest in improving nutrition, roads, infrastructures and information systems to enable good food saturation and availability in the country(13). In addition, access to markets, healthcare facilities, communal education especially of women and young people is essential to improve nutritional levels in rural regions, generally improving access and social services would positively impact nutrition of children. Yourkavitch and colleagues found differences in health indicators in different geographic areas, and suggested that in order to improve health, these access differences needed to be addressed to reduce health inequalities (14). Others have also noted that an equity focused approach leading to improvement in effective intervention coverage results in sharp decreases in child mortality and stunting and higher cost-effectiveness (15).

In addition to poor social services we found out that poverty was a major contributor to malnutrition. Most families did not have enough food for their families. Pena and Bacalloa made a similar observation almost two decades ago in their paper Malnutrition and Poverty noting that unequal distribution of 
income has an independent effect on health indicators in improving health and reducing poverty (16). Muhoozi and colleagues (17) found out that under nutrition among infants living in impoverished rural South Western Uganda, was associated with poverty and low dietary diversity (17).

Similarly (18) highlighted the interconnection between malnutrition, poverty, and chronic diseases in Uganda indicating that each of the factors influences the presence and permanence of the other, resulting in a synergistic impact. Thus to improve the nutrition status in Uganda, there is need to improve the economy which would translate to improved income and standard of living. Furthermore, two decades ago, Smith and Haddad determined that increases in income at the individual and national levels leads to improvement in child nutritional status since increase in household income lead to increase in food availability, education especially of girls, improvement in the status of women and the quality of the health environment along with the added investment in child nutrition (19). A study in Eastern and Western Uganda, suggested that the cost of food items were major barriers to trying new ways of improving their children's nutrition (20). In contrast some studies have reported that behaviour change in terms of the quality and quantity of care provision, micronutrient supplementation, food fortification and diet supplementation for pregnant women that are essential to reducing under nutrition do not solely rely on increase in income (21). Other factors such as maternal depression has a strong negative impact on child nutrition and development since depressed mothers provide inadequate care and diets for their children (22). Thus there is need to support conditions that strengthen nutrition goals and actions that optimize women's nutrition, time, physical and mental wellbeing as well as women empowerment (23).

Alcoholism and domestic violence were also found out to be factors responsible for persistent malnutrition in this study in Buhweju district. Previous studies in a general hospital attached to a medical college in India showed that, children of alcoholics are more likely to be malnourished and at high risk for physical abuse (24). Our findings compare with those of Yount and colleagues (25) who highlighted that domestic violence is a global public health problem and that domestic violence against women affects early childhood growth and nutrition through biological and behavioural pathways with prenatal domestic violence resulting in low birth weight which is a strong predictor of subsequent growth (25), (26).

Participants in this study pointed out that, children in Buhweju district were malnourished because childcare services were inadequate. Inadequate child care services were mainly due to maternal level of knowledge on child care rearing practices. Authors in a nutrition education program and community comparison group in Uganda noted that, maternal personal - factors shaped their ability to leverage resources to provide care to their children especially child nutrition, hygiene, access to health care and general household sanitation (27). As noted in the background, the earlier study (2016) in Buhweju district by Tumwesigye, Tushemerirwe et al. reported that low access to appropriate complementary diets, poor socioeconomic status, and low knowledge were the main predictors of childhood stunting. In another study in Northern Uganda by Mukunya and colleagues, also noted the association of the prevalence of under nutrition, wasting and stunting with rural residence and and limited caregiver knowledge of best practices in terms of Integrated Management of Childhood Illnesses (C-IMCI) (28). 


\section{Policy Implications}

Whereas Ministry of Health has policies in place to fight malnutrition in Children in Uganda, based on the findings of this study, we suggest that more should be done to revise and implement these policies to address the persistent malnutrition in Buhweju district. The factors highlighted in this study must be addressed from the grassroots. There is a need for individual and community multisectoral interventions that aim to address many of the factors. The observation that members of the communities already have insight into the factors suggests fertile ground for factor related interventions, For example, ensuring that immunization and deworming are seen as important and that these are both available when the mothers bring their children to the health centre; educating mothers on how best to ensure a broader diet; work with elders and village leaders to decrease acceptance and perception of alcoholism and domestic violence and enhancing the role and importance of fathers in providing for their children has potential for significant impact .

\section{Strengths and Limitations of the Study}

The results of this study reflect the views and opinions of the Healthcare providers and caretakers' of children 0-59months in Buhweju district. The agreement in their views and opinions is the key strength of this study. The other strength is our ability to work with key stakeholders with respect to childhood nutrition in rural communities like communities of Buhweju district. However, since our key informants were employees of Buhweju district local government, this may have acted against us as they may have feared to fully express their views and opinions for the fear of that their employer may access this information. However, during the informed consent process, we assured all our participants of anonymization and confidentiality. We acknowledge that this study presents views and opinions of caretakers and Village Health Team members in the two sub counties of Buhweju district, we may be missing the experiences of the same in the other eleven (11) sub counties who were not selected, however this reflects the views and opinions of the caretakers and VHTs in the subcounties that are hard hit by malnutrition and key stakeholders in the nutrition programme of Buhweju district.

\section{Conclusions}

Persistent malnutrition in children aged 0-59 months in Buhweju district is mainly due to historical and geographical challenges and its associated factors that include poverty and economic occupation, parental alcoholism and domestic violence and inadequate childcare services. Addressing these factors from the grassroots up through, multisectoral collaboration between infrastructure, Agriculture and health, engaging communities and effective policy changes and implementation has the potential to improve the nutrition status of children in Buhweju district.

\section{List Of Abbreviations}


C-IMCl- Caregiver knowledge of best practices in terms of Integrated Management of Childhood Illnesses.

DHO-District Health Officer

FGD-Focus Group Discussion

HIV-Human Immune Deficiency Virus

KII- Key Informant Interviews

MUST -Mbarara University of Science and Technology

SAM- Severe Acute Malnutrition

SDGs-Sustainable Development Goals

VHT-Village HealthTeam

WHO-World Health Organisation

\section{Declarations}

\section{Acknowledgements}

The authors appreciate the great work done by Nabaasa Patience (NP) the research assistant for her dedication to data collection and transcription. The participants in the study are greatly appreciated for their participation.

\section{Funding}

The study received peer reviewed funding from MicroResearch Grant Number16N_MUS_001 under the institute of Maternal and Newborn and Healthy Child Uganda at Mbarara University of Science and Technology (MUST). The funding award sought to support Junior Faculty in Research Training and conduct at Mbarara University of Science and Technology. The Microresearch Canada had no role in design of study, data collection and analysis, interpretation of data or writing of manuscript.

\section{Availability of data and materials}

To ensure confidentiality of participants' information as agreed up on during Ethical approval and Consent Process, qualitative interview transcripts and the corresponding anonymised Atlas ti7.5 file are only visible to the direct research team, and are not publically available

\section{Authors Information}

CA is a Lecturer in the Department of Medical Laboratory Science and SA is a Lecturer in the Department of Human Anatomy at Mbarara University of Science and Technology (MUST). GZR is a Senior Lecturer 
in the Department of Psychiatry, Mbarara University of Science and Technology. Atukunda Susan Pearl (ASP) is a Nutritionist at Uganda Industrial Research Institute. Susan Campisi (SC) is an international mentor on the MicroResearch Grant. She based at the University of Toronto and the Hospital for Sick Children in Toronto; Canada.

\section{Author contributions}

All authors contributed to the design of the study and writing of the manuscript. CA and GZR and SA did the data analysis. SC provided scientific guidance throughout the project. All authors read and approved the final manuscript.

\section{Ethics approval and consent to participate}

This study received ethical approval from the Mbarara University of Science and Technology Research Ethics Committee (MUST REC) MUREC1/7 and Uganda National Council of Science and Technology (UNCST) SS4701.

Written informed consent was obtained from all participants. For participants who were unable to read and write, the written consent was read out by a research team member, the participant would be given an opportunity to ask questions, the questions would be answered until he/she is satisfied. His/her informed consent would be signed by thumb print if in agreement in presence of a Research Assistant and a witness.

\section{Consent for Publication}

Not Applicable

\section{Competing interests}

The authors declare that they have no competing interests.

\section{References}

1. De Onis M, Branca F. Childhood stunting: a global perspective. Maternal \& child nutrition. 2016;12:1226.

2. Kitsao-Wekulo P, Holding P, Taylor HG, Abubakar A, Kvalsvig J, Connolly K. Nutrition as an important mediator of the impact of background variables on outcome in middle childhood. Frontiers in human neuroscience. 2013;7:713.

3. De Onis M, Dewey KG, Borghi E, Onyango AW, Blössner M, Daelmans B, et al. The W orld H ealth O rganization's global target for reducing childhood stunting by 2025: rationale and proposed actions. Maternal \& child nutrition. 2013;9:6-26.

4. Tigga PL, Sen J, Mondal N. Effects of some socio-economic, demographic and life style factors on the prevalence of thinness among pre-school children. Epidemiology, Biostatistics and Public Health. 
2015;12(1).

5. Ickes SB, Jilcott SB, Myhre JA, Adair LS, Thirumurthy H, Handa S, et al. Examination of facilitators and barriers to home-based supplemental feeding with ready-to-use food for underweight children in western Uganda. Maternal \& child nutrition. 2012;8(1):115-29.

6. Habaasa G. An investigation on factors associated with malnutrition among underfive children in Nakaseke and Nakasongola districts, Uganda. BMC pediatrics. 2015;15(1):134.

7. Nankinga O, Kwagala B, Walakira EJ. Maternal employment and child nutritional status in Uganda. PloS one. 2019;14(12).

8. Tumwesigye NM, Tushemerirwe FB, Kajjura R, Nabunya V, Naitala RA, Namanda C. Nutritional status, feeding practices and state of other related indicators at onset of a multi-model community nutrition intervention program in Mpigi District, Uganda. African health sciences. 2016;16(4):892-903.

9. Statistics UBo, ICF. Uganda demographic and health survey 2016: key indicators report. UBOS, and Rockville Maryland; 2017.

10. Bukusuba J, Kaaya AN, Atukwase A. Predictors of Stunting in Children Aged 6 to 59 Months: A Case-Control Study in Southwest Uganda. Food and nutrition bulletin. 2017;38(4):542-53.

11. Kikafunda JK, Walker AF, Collett D, Tumwine JK. Risk factors for early childhood malnutrition in Uganda. Pediatrics. 1998;102(4):e45-e.

12. Kikafunda J, Agaba E, Bambona A. Malnutrition amidst plenty: an assessment of factors responsible for persistent high levels of childhood stunting in food secure Western Uganda. African Journal of Food, Agriculture, Nutrition and Development. 2014;14(5):2088-113.

13. Dieleman JL, Sadat N, Chang AY, Fullman N, Abbafati C, Acharya P, et al. Trends in future health financing and coverage: future health spending and universal health coverage in 188 countries, 2016-40. The Lancet. 2018;391(10132):1783-98.

14. Yourkavitch J, Burgert-Brucker C, Assaf S, Delgado S. Using geographical analysis to identify child health inequality in sub-Saharan Africa. PLoS ONE. 2018;13(8):e0201870.

15. Carrera C, Azrack A, Begkoyian G, Pfaffmann J, Ribaira E, O'Connell T, et al. The comparative costeffectiveness of an equity-focused approach to child survival, health, and nutrition: a modelling approach. The lancet. 2012;380(9850):1341-51.

16. Pena M, Bacallao J. Malnutrition and poverty. Annual review of nutrition. 2002;22(1):241-53.

17. Muhoozi GK, Atukunda P, Mwadime R, Iversen PO, Westerberg AC. Nutritional and developmental status among 6-to 8-month-old children in southwestern Uganda: a cross-sectional study. Food \& nutrition research. 2016;60(1):30270.

18. Adebisi YA, Ibrahim K, Lucero-Prisno III DE, Ekpenyong A, Micheal Al, Chinemelum IG, et al. Prevalence and Socio-economic Impacts of Malnutrition Among Children in Uganda. Nutrition and Metabolic Insights. 2019;12:1178638819887398.

19. Smith LC, Haddad LJ. Explaining child malnutrition in developing countries: A cross-country analysis: Intl Food Policy Res Inst; 2000. 
20. Bekele $\mathrm{H}$, Turyashemererwa F. Feasibility and acceptability of food-based complementary feeding recommendations using Trials of Improved Practices among poor families in rural Eastern and Western Uganda. Food science \& nutrition. 2019;7(4):1311-27.

21. Dary O, Mora JO. Food fortification to reduce vitamin A deficiency: International Vitamin A Consultative Group recommendations. The Journal of nutrition. 2002;132(9):2927S-33S.

22. Ashaba S, Rukundo GZ, Beinempaka F, Ntaro M, LeBlanc JC. Maternal depression and malnutrition in children in southwest Uganda: a case control study. BMC public health. 2015;15(1):1303.

23. Ruel MT, Alderman H, Maternal, Group CNS. Nutrition-sensitive interventions and programmes: how can they help to accelerate progress in improving maternal and child nutrition? The lancet. 2013;382(9891):536-51.

24. Rao KN, Begum S, Venkataramana V, Gangadharappa N. Nutritional neglect and physical abuse in children of alcoholics. The Indian Journal of Pediatrics. 2001;68(9):843-5.

25. Yount KM, DiGirolamo AM, Ramakrishnan U. Impacts of domestic violence on child growth and nutrition: a conceptual review of the pathways of influence. Social science \& medicine. 2011;72(9):1534-54.

26. Yount KM, Halim N, Hynes M, Hillman ER. Response effects to attitudinal questions about domestic violence against women: A comparative perspective. Social Science Research. 2011;40(3):873-84.

27. Ickes SB, Heymsfield GA, Wright TW, Baguma C. "Generally the young mom suffers much:" Sociocultural influences of maternal capabilities and nutrition care in Uganda. Maternal \& child nutrition. 2017;13(3):e12365.

28. Mukunya D, Kizito S, Orach T, Ndagire R, Tumwakire E, Rukundo GZ, et al. Knowledge of integrated management of childhood illnesses community and family practices $(\mathrm{C}-\mathrm{IMCl})$ and association with child undernutrition in Northern Uganda: a cross-sectional study. BMC public health. 2014;14(1):976.

\section{Supplementary Files}

This is a list of supplementary files associated with this preprint. Click to download.

- InterviewGuides.docx 